ally there are examples of special pleading. Granit complains of neglect to read carefully the papers containing evidence in favour of alpha innervation of intrafusal muscle fibres. Certainly the experiments of Barker and Laporte and their respective co-workers leave no doubts in our minds that some motor fibres, larger than gamma, branch to supply both intra and extrafusal muscle. The more carefully one reads these papers, however, the more one doubts whether the early response of the primary spindle afferent fibres is due to an alpha motor innervation. Only more direct evidence on this point will convince the sceptics and perhaps it is with the hope of promoting fresh experiment that Granit writes so challengingly. Indeed, throughout the book ideas for future experiments are tossed about. The general has retired but he leaves no doubt where his successors should attack.

The book is on the whole well produced, the bibliography is extensive and well indexed. This alone will make it invaluable in teaching. Some illustrations are substandard. A full page reproduction of a figure from Boyd's work in the Philosophical Transactions of the Royal Society is rendered meaningless, the more the pity, for the journal is not available in all libraries. Some illustrations lose their impact by excessive reduction, and one cannot help feeling that legends which are suitable in the original paper are not always so in a work such as this. Having pointed out some blemishes I rush to say that I would unhesitatingly recommend the book to neurophysiologists, to neurologists with a good grounding in neurophysiology and possibly to engineers-but they may need a guiding hand.

J. E. PASCOE

\section{Population Control}

The Growth and Control of World Population. By W. D. Borrie. (The Advancement of Science.) Pp. $x+340$. (Weidenfeld and Nicolson: London, November 1970.) 60s.

Books on "the population problem" seem to be growing at a rate similar to their subject matter. Demography is no longer the Cinderella of the social sciences, and though it would be immodest to agree with the jacket of this book that it is "the important subject", it is flattering that it should be so described. Inevitably, with the growth of public interest, it is the extremist prognoses which receive the greatest attention. At present it is the prophets of unmitigated doom who hold the stage, but there are also those eternal optimists who believe that the problem will solve itself. There is a great need for a concise introduction to the current demographic situation of the world which, while giving consideration to the views of the extremists, does not lie in either camp. This book fulfils that need.

Professor Borrie sets out to examine the chief demographic themes in history which have led to the current situation; this is mapped out in chapters devoted to the demographic patterns of the three third world continents, Europe and overseas European countries. A point which is well brought out in this book, but which is often overlooked, is the particular demographic features of each of the third world continents-features which are as important as the general similarities. Africa still has unacceptably high mortality rates and the potential for growth there has not yet been fully realized. South America may be able to accommodate its natural increase for a short time, though a limitation which Borrie does not discuss is the rapid rate of urbanization and the demographic consequences of this process. In fact, greater attention could have been paid to the general subject of urbanization and the distribution of population concentrations within countries, while the length of the chapter on the great overseas migrations, which are essentially of the past, could have been reduced. This disproportionate attention to European overseas migration is understandable, however, as the author comes from the Australian National University.

Although the current emphasis in demographic work is on the need for fertility reduction, Borrie shows that throughout the third world, levels of life expectancy are still unacceptably low. Increases in life expectancy must to a degree increase the difficulty of fertility reduction, for third world countries are still a long way from the state of "demographic immortality", a somewhat obscure term he uses to mean the situation where virtually every person born can expect to survive to the end of their reproductive period.

The chapter on "Population Policies and the State" shows how specific governmental policies have had little effect on the change from high to low and controlled fertility, although measures primarily adopted for socio-medical reasons, such as legalizing abortion, have sometimes had demographic side effects. Measures to reduce further fertility levels in western countries would have to go beyond the generally accepted limits of democratic government.

The introduction of the demographic concept of life expectancy, and its symbol $\left(\mathrm{e}_{\mathrm{o}}^{\mathrm{o}}\right.$ ), without explanation early in the book should have been avoided. A misreading of a full stop as a zero has inflated Ceylon's population on page 118 to 607 million (standing room only, indeed), while the first truly national census in 1703 was in Iceland and not Ireland as stated on page 23 . These are, however, small points which cannot detract from a refreshing book which concludes by pointing out that the demographic growth rates of today are a reflexion of the triumph of man over environment, through the application of science. The triumph still has to be completed by bringing fertility into line with low mortality levels and, to achieve this, third world countries must follow a course not taken by the west; the reduction of fertility before the general spread of the social and economic consequences of industrial growth, but premonitions of failure are as yet unjustified.

D. R. COPE

\section{Theory of Coherence}

Coherent Light. By A. F. Harvey. Pp xxxvi+1329. (Wiley Interscience: London and New York, December 1970.) 360s.

IT is in no way disparaging to say that the most valuable thing about this book is its list of references. On average something like 400 references are given at the end of each of the twenty-eight chapters. As the reference includes not just the author and journal but also the title of the paper cited, the value of such a bibliography, based as it is primarily on work of the last ten years, cannot be over estimated.

Dr Harvey has produced an enormous volume of a size which is usually produced by a group of authors coordinated by an editor. The fact that he has compiled the volume single-handed would lead one to hope that the overall content should be more of a piece than one usually expects in a wide-ranging volume of this kind, and the hope is justified. The title of the book, however, is somewhat misleading. The theory of coherence from a classical standpoint is certainly much better reviewed in chapter 10 of Born and Wolf's Principles of Optics, and the quantized field approach of Glauber is simply not reviewed in this book at all.

The title in fact seems not to explain very well the author's intentions. $\mathrm{He}$ sets out to compile a detailed account of the work associated with the creation and use of sources possessing spatial and temporal coherence in the range from submillimetre waves to the ultraviolet, and chooses to aim at the engineer or applied physicist using the devices rather than the physicist concerned with fundamental ideas. Consequently the theory of coherence, of lasers and of non-linear optics are all better expounded in other books. But at the level chosen, and given the splendid bibliography, the volume is undoubtedly a valuable source of reference. The author is well served by his publisher in terms of the quality of the production, but at this price presumably even some libraries will ask themselves if they are not better off buying three or four other books in this area for the same money.

L. Allen 